\title{
FILTER FEEDING ALLOGENIC ENGINEERING OPTIMIZATION ALGORITHM FOR ECONOMIC DISPATCH
}

\author{
MBAE ARIEL MUTEGI \& NWULU NNAMDI \\ University of Johannesburg.
}

\begin{abstract}
The main objective of the economic dispatch problem in a power system is to minimize the total thermal fuel cost of the committed generators while satisfying the various system equality and inequality operational constraints. This research developed a new optimization algorithm, named the filter feeding allogenic engineering algorithm, for use in solving the economic dispatch problem. This meta-heuristic algorithm has been inspired by the filter feeding and motile behaviour of allogenic engineers. The newly developed algorithm was formulated using the Matlab software environment, and its performance was tested using the IEEE 39-Bus, 10-Generator system. A comparative analysis was also conducted with the Ant lion optimization heuristic algorithm, and the obtained results indicate that the filter feeding allogenic engineering algorithm yields superior performance.

Keywords: allogenic engineering, constraints, economic dispatch, heuristic and optimization.
\end{abstract}

\section{INTRODUCTION}

Thermal, nuclear, variable renewables and hydropower are the major sources of electric power generation. Power system operational economics is very important for thermal generators as the variable costs are much higher when compared to the other types of generation. Fuel cost accounts for the bulk of the operational cost of a power system. The goal for power system operators, therefore, is to minimize the fuel and other associated costs. This, in essence, is the economic dispatch (ED) problem. It is the process of allocating generation among the committed generation units while satisfying the applicable constraints and minimizing the energy requirements. It is for this reason that research into optimal economic dispatch solution continues to attract a lot of research attention as the sector unbundling and competition take shape across the world. This is in tandem with concurrent research on how to manage and curtail the burgeoning electricity demand in order to minimize harmful emissions [1-4].

Several constraints have to be taken into account during the ED problem formulation. These include, but not limited to, the types of generating units, transmission constraints, system reliability assessment, operating limits of each machine, permissible running time for each machine, machine ramp rate, variable generator operating costs, cost of environmental compliance, machine start-up cost, must run units (for voltage support), spinning reserve requirement, base load and renewable energy technologies in use among other constraints. A key constraint is due to the incorporation of large-scale renewables and how to ensure power system reliability is maintained due to the intermittent nature of renewables [5-6].

A number of optimization methods are used to solve the economic dispatch problem in a power system. They are broadly grouped into three, namely the classical, heuristic and hybrid optimization methods.

The classical methods include, but not limited to, the gradient method [7], calculus method, Lagrange relaxation method, Hessian-based method, Newton-based method, interior point method, geometric programming method, dynamic programming method, integer programming method, stochastic programming method, multi-objective programming method, quadratic programming method, power search algorithm [8], general algebraic, probable loads variation [9] and the linear as well as nonlinear programming methods [10]. These 
methods have convergence challenges occasioned by the nonlinear nature of the problem and have to deal with many variable constraints besides having a high computational time. They have no guarantee of achieving a global optimum because they start from a single point instead of a population, and thus, most times converge to a local optimum.

The heuristic methods give better results due to their robust nature. They are designed to search for the best possible solution with a very high degree of computational efficiency. They include, but not limited to, the ant colony search algorithm [11], genetic algorithm [12], particle swarm optimization [13], cuckoo search, theory of games [14], Vikor method [15], flower pollination algorithm [16], exchange market algorithm [17], harmony search [18], across neighbourhood [19], whale optimization [20], kinetic gas molecule optimization [21], immune log-normal evolutionary programming algorithm [22] and social spider algorithm [23].

Hybrid methods seek to take advantage of specific strengths of each of the individual methods. Examples include chaotic particle swarm optimization and sequential quadratic programming, differential evolution and genetic algorithm, hybrid krill heard algorithm and bee algorithm and tabu search, particle swarm optimization algorithm based on the Pareto criterion and fuzzy logic [24], hybrid of firefly and Bat algorithms [25], firefly and the levy flights algorithm [26], an hybrid of ant colony optimization-artificial bee colony-harmony search [27], hybrid Grey Wolf optimization [28] and a combination of continuous grasp algorithm and differential evolution [29].

There has been continuous and sustained effort to develop new heuristic optimization methods inspired by the behaviour of natural organism and plants, natural occurrences and various laws of science. Good recent examples include immune algorithm [30], lightning flash algorithm [31] teaching-learning-based optimization algorithm [32], symbiotic organism search algorithm [33], enhanced firework algorithm [34], modified differential evolution [35], adaptive charged system search algorithm [36], distributed auction optimization algorithm [37], water cycle algorithm [38] and mine blast algorithm [39]. Development of new hybrid methods such as the immune evolutionary programming has also grown [40].

From the foregoing analysis, it is evident that the development of new improved nature-inspired meta-heuristic and hybrid optimization methods will continue to grow in the foreseeable future as power systems become more complex. It is for this reason that this research sought to develop a new method of optimization named the filter feeding allogenic engineering (FFAE) algorithm whose results were compared with the ant lion algorithm (ALO). The algorithm is inspired by the filter feeding and the environmental stimuli motile behaviour of allogenic engineers.

The rest of this article is organized as follows: Section 2 gives the mathematical formulation for the economic dispatch problem, while section 3 details the developed algorithm. Section 4 presents the numerical simulations, results and discussions. Finally, section 5 gives the conclusion of the work and presents areas for improvement.

\section{FORMULATION OF THE ECONOMIC DISPATCH PROBLEM}

The static total cost of production $F$ for the 39-Bus, 10-Generator IEEE test system is given as follows:

$$
F=\sum_{i=1}^{9} C_{i} P_{i}
$$

where $C_{i} P_{i}$ is the cost of production for the $i$ th generator which can be modelled using the quadratic function:

$$
C_{i} P_{i}=a P_{i}^{2}+b P_{i}+c
$$


where $a, b$ and $c$ are the $i$ th generator cost coefficients.

The objective, therefore, is to minimize eqn (1) subject to the following equality and inequality constraints:

$$
\begin{gathered}
P_{i(\min )} \leq P_{i} \leq P_{i(\max )} \\
P_{\text {generated }}=P_{\text {loss }}+P_{\text {demand }}
\end{gathered}
$$

The system losses are expressed as follows:

$$
\begin{gathered}
P_{\text {loss }}=\sum_{k=1}^{9} g_{k}\left[V_{i}^{2}+V_{j}^{2}-2 V_{i} V_{j} \cos \left(\delta_{i}-\delta_{j}\right), k \in\{1,2,3 \ldots . l\}\right. \\
=\sum_{i=1}^{9} \sum_{j=1}^{9} P_{i} B_{i j} P_{j}+\sum_{i=1}^{9}\left(B_{0 i} P_{i}+B_{00}\right)
\end{gathered}
$$

where $g_{k}$ is the conductance of the $k$ th line; $V_{i}$ and $\delta_{i}$ are the voltage magnitude and angle of bus $i$, respectively; $V_{j}$ and $\delta_{j}$ are the voltage magnitude and angle of bus $j$, respectively; $B_{i j}$, $B_{0 i}$ and $B_{00}$ are the elements of the transmission loss coefficient matrix $\mathbf{B}$; and $l$ is the number of lines in the system [40].

The proposed optimization algorithms are employed to solve models given by Eqs. (1)-(5) in order to obtain the values of generator output, system incremental fuel cost and the power loss for the given load demand.

\section{DEVELOPED ALGORITHMS}

\subsection{Filter feeding allogenic engineering algorithm}

Filter feeding allogenic engineering is rooted in oceanography and is inspired by the feeding and motile behaviour of allogenic engineers (part of ecosystem engineers), such as herring clams, sponges, baleen whale, krill and ameboid protozoa. Ecosystem engineers affect the availability of resources to other organisms either from a direct result of the structure that they create (autogenic engineers) or by the modulation of biotic and abiotic forces caused by their structure and biological activity (allogenic engineers). Allogenic engineers remove large quantities of suspended material from the water by filter feeding as they move around largely due to stimuli caused by food nutrients within their environment. They affect the availability of resources to other organisms by the modulation of biotic and abiotic forces through their body structure and biological activity. They are able to interfere with abiotic factors such as water residence time, hydrodynamic conditions and availability of light by water filtration, thus providing a residential habitat for other marine species [41].

As a result of the response to various stimuli, actively moving away or towards the environmental stimuli, the allogenic engineers act as environmental monitors, e.g. if something in the water goes bad, they are the first to show the effects. This is the inspiration used to develop this optimization method. The power network environment will be scanned in real time for set parameters so as to determine the global optimal solution for the minimal fuel cost and losses in the same way the allogenic engineers respond to real time stimuli in the water environment [42-44].

The equation below shows the time rate of change of a given nutrient-main stimuli for allogenic engineers' movement in sea water: 


$$
\frac{d_{c m}}{d t}=\left(k_{m}-\sum_{n=1}^{N} k_{m n} c_{n}-k_{h}\right) c_{m}+k_{h} c_{m o}
$$

where $c_{m}$ is the concentration of a given nutrient in sea water; $N$ is the total number of constituents (dependent variables); $c_{m o}$ is the most influential chemical in the given water ecosystem, e.g. nitrogen; $t$ is the time; $k_{m}$ is the net production rate of the given nutrient-minus natural decay, respiration and sinking processes; $k_{m n}$ is the rate coefficients for uptake of $c_{m}$ by other constituents $c_{n}$; and $k_{h}$ is the reciprocal of the hydrodynamic residence time.

The above equation takes care of a large number of coefficients, the majority of which are a function of $c_{n}$, light, temperature and turbidity. It can be reduced to the prey-predator equations written as follows:

$$
\begin{gathered}
\frac{d P}{d t}=k_{p}-\frac{F}{h} B P \\
\frac{d B}{d t}=-k_{b} B+\alpha \beta_{1} \beta_{2} F P B
\end{gathered}
$$

where $P$ is a given nutrient concentration; $B$ is the filter feeders population; $k_{p}$ is the given nutrient growth rate; $k_{b}$ is the filter feeders mortality rate; $F$ is the specific filtration rate for a given filter feeder; $h$ is the water depth; $\alpha$ is the conversion coefficient of the most influential chemical component, e.g. nitrogen to the given type of nutrient; $\beta_{1}$ is the (filter feeders) feeding efficiency; and $\beta_{2}$ is the filter feeders nutrient conversion coefficient.

Equation (7) shows that the time rate of increase of a given nutrient equals the most influential chemical conversion efficiency minus the rate of removal through filter feeding. The iterative determination of $\alpha, \beta_{1}, \beta_{2}, k_{p}$ and $k_{b}$ is used to solve for $P$ and $B$. The highest nutrient concentration $(P)$ will act as the stimuli to attract the largest number of filter feeders $(B)$ which will be our optimal solution equivalent to given generator outputs and power losses obtained by solving eqn (5) [44].

The particular load data and generators with set power output constraints will be equated to given parameters that affect the nutrient(s) concentration in the sea water. This is the stimulus that normally results in the movement of a majority of allogenic engineer species towards the direction with the highest nutrient concentration in the sea. The optimization will begin with a number of initial solution guesses, and after a few iterations, Kalman filtration will be applied to zero in on the most probable solutions which will be iterated to the end. The filtration process will be used to predict which of the initial guesses has higher chances of convergence by way of walking the entire probability distribution of each after a few iterations. This enables mathematical distinction between phenomena and noumena by way of a complete statistical characterization of the estimation problem at hand [45].

\subsection{Ant lion optimization algorithm}

This is a population-based algorithm that is inspired by the hunting behaviour of ant lions. It mimics the ant lion's five hunting steps namely, random ant (prey) walks, traps building, entrapment of ants in the said traps, catching prey and finally re-building the traps [46-48].

The ant lions dig cone-shaped traps and hide at the bottom as they wait for their prey to trip and fall into the trap that normally has sharp edges. Once the prey (other ants and insects) has 
no escape route, the ant lions simply attack, kill and eat their hunt after which they improve the trap for the next hunt. Often, the prey tries to escape and the ant lions throw soil at the trap's sharp edges to ensure that the prey slides back to the deepest end of the trap. The hunters further employ delay tactics to increase the prey's level of malnutrition as well as digging the traps while facing away from the moon surface for maximum darkness. Given that ants move at random in search of food, a random walk is normally chosen to model ants' movement. During optimization, these random ant walks are normalized so as to keep them moving within a given search space. The ant lion pits are modelled by a mathematical equation with given boundary conditions. To increase the chances of fitter ant lions catching prey, their hunting ability is modelled using a roulette wheel operator so as to select the finest and fittest ant lions.

The random ant walk is modelled as follows:

$$
X(t)=\left[0, \operatorname{cumsum}\left(2 r\left(k_{1}\right)-1\right), \operatorname{cumsum}\left(2 r\left(k_{2}\right)-1, \ldots, \operatorname{cumsum}\left(2 r\left(k_{T}\right)-1\right)\right]\right.
$$

where $T$ and $k$ represent the maximum and step number of iterations, respectively, and cumsum is the total sum.

A random function $r(t)$ is defined as follows:

$$
r(t)=\left\{\begin{array}{l}
1, \text { for rand }>0.5 \\
0, \text { for rand } \leq 0.5
\end{array}\right.
$$

where rand is a random number generated with uniform distribution function within the range $0-1$. The random ant walks are normalized so as to keep them within a defined range using the equation:

$$
X_{h}^{t}=\frac{\left(X_{h}^{k}-a_{h}\right)\left(d_{h}-C_{h}^{k}\right)}{\left(d_{h}^{k}-a_{h}\right)}+C_{h}
$$

where $a_{h}$ and $d_{h}$ are the minimum and maximum values of the random ant walks of variables $h$ th; $c_{h}^{k}$ and $d_{h}^{k}$ are the minimum and maximum value of $h$ th variables at the $k$ th iteration. The mathematical model of the ant lion's hyperspherical pit is given by

$$
\begin{aligned}
& c_{h}^{k}=\text { Antlion }_{j}^{k}+c^{k} \\
& d_{h}^{k}=\text { Antlion }_{j}^{k}+d^{k}
\end{aligned}
$$

where is the antlion's $j$ th position at iteration $k$ th.

When the ant falls into the trap, the ant lion throws sand towards the door so as to force it to the deepest end of the hole. This reduction of the ant's walk hyper-sphere is modelled as follows:

$$
\begin{gathered}
c^{k}=\frac{c^{k}}{I} \\
d^{k}=\frac{d^{k}}{I}
\end{gathered}
$$




$$
I=10 w * \frac{k}{T}
$$

where $w$ is a constant speed on the current iteration number.

Killing the hunt and improving the trap again for the next catch is modelled as follows:

$$
\text { Antlion }_{j}^{k}=\left\{\text { Antlion }_{h}^{k}, \text { if } f\left(\text { Antlion }_{h}^{k}\right) \geq f\left(\text { Antlion }_{j}^{k}\right)\right\}
$$

The elitism of the ant lion is determined using the roulette wheel modelled as follows:

$$
A n t_{h}^{k}=\frac{R_{A}^{k}+R_{E}^{k}}{2}
$$

where $R_{A}^{k}$ and $R_{E}^{k}$ are the random choices of the ant lion using the roulette wheel and around the elite at the kth iteration, respectively.

\section{NUMERICAL SIMULATIONS, RESULTS AND DISCUSSION}

\subsection{Methodology}

The 39-Bus IEEE test system was used to test the developed algorithm on the economic dispatch problem. The single line diagram of the system is shown in Fig. 1.

The generator data used had an operational constraint of $10 \%-90 \%$ of the rated value as per Table 1.

The total connected load varies from 100 MW to a maximum of $4993 \mathrm{MW}$ as shown in Table 2.

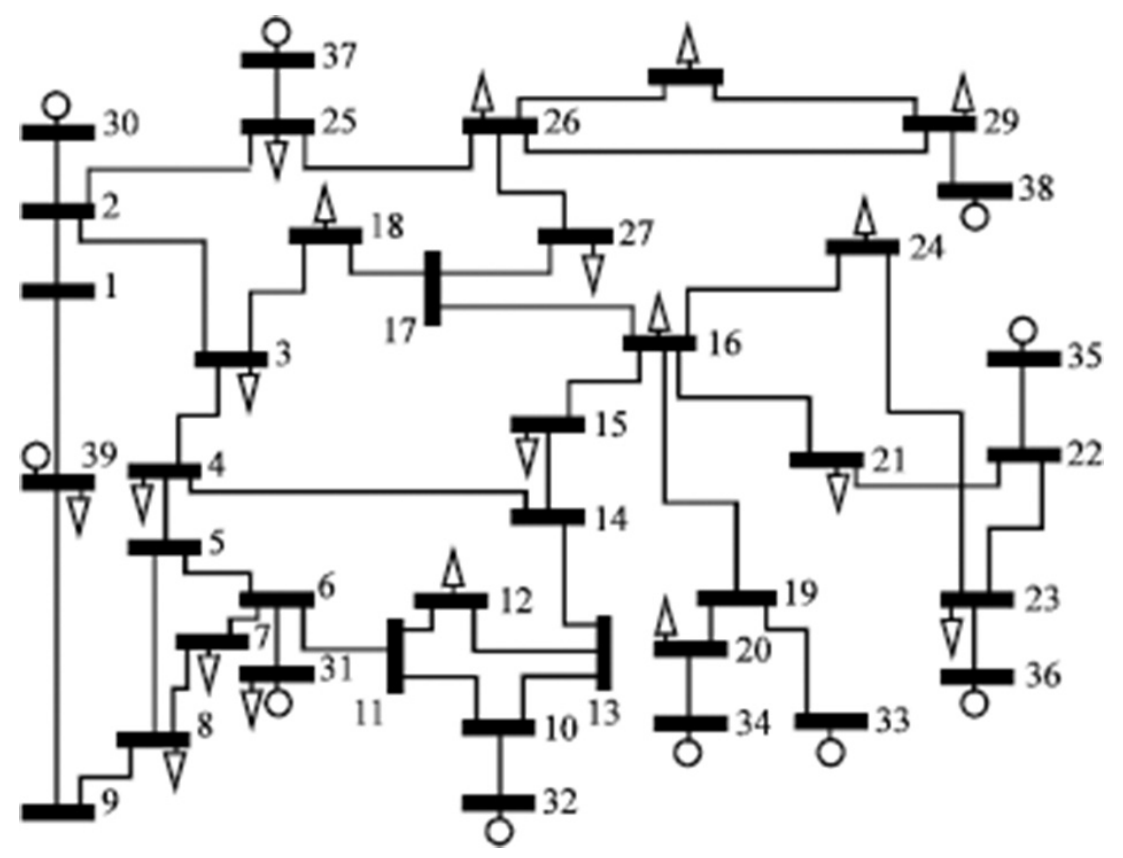

Figure 1: The IEEE 10-Generators, 39-Bus test system. 
Table 1: IEEE 39-Bus generator data.

\begin{tabular}{lllll}
\hline & Rated $(\mathbf{M W})$ & Min $(\mathbf{M W})$ & Max $(\mathbf{M W})$ & $\mathbf{\$} / \mathbf{h}$ \\
\hline Gen10 & 250 & 25 & 225 & 525 \\
Gen3 & 650 & 65 & 585 & 460 \\
Gen4 & 632 & 63 & 568.8 & 455 \\
Gen5 & 508 & 50 & 457.2 & 510 \\
Gen6 & 650 & 65 & 585 & 420 \\
Gen7 & 560 & 56 & 504 & 475 \\
Gen8 & 540 & 54 & 486 & 490 \\
Gen9 & 830 & 83 & 747 & 440 \\
Gen1 & 1000 & 100 & 900 & 415 \\
Total & $\mathbf{5 6 2 0}$ & $\mathbf{5 6 1}$ & $\mathbf{5 0 5 8}$ & \\
\hline
\end{tabular}

Table 2: IEEE 39-Bus connected load data.

\begin{tabular}{llll}
\hline & & & Load \\
Bus & Type & MW & MVar \\
\hline 3 & PQ & 322 & 2.4 \\
4 & PQ & 500 & 184 \\
7 & PQ & 233.8 & 84 \\
8 & PQ & 522 & 176 \\
12 & PQ & 7.5 & 88 \\
15 & PQ & 320 & 153 \\
16 & PQ & 329 & 32.3 \\
18 & PQ & 158 & 30 \\
20 & PQ & 628 & 103 \\
21 & PQ & 274 & 115 \\
23 & PQ & 247.5 & 84.6 \\
24 & PQ & 308.6 & -92 \\
25 & PQ & 224 & 47.2 \\
26 & PQ & 139 & 17 \\
27 & PQ & 281 & 75.5 \\
28 & PQ & 206 & 27.6 \\
29 & PQ & 283.5 & 26.9 \\
31 & PQ & 9.2 & 4.6 \\
\hline & & $\mathbf{4 9 9 3 . 1}$ & \\
\hline & & & $\mathbf{1 1 5 9 . 1}$ \\
\hline
\end{tabular}




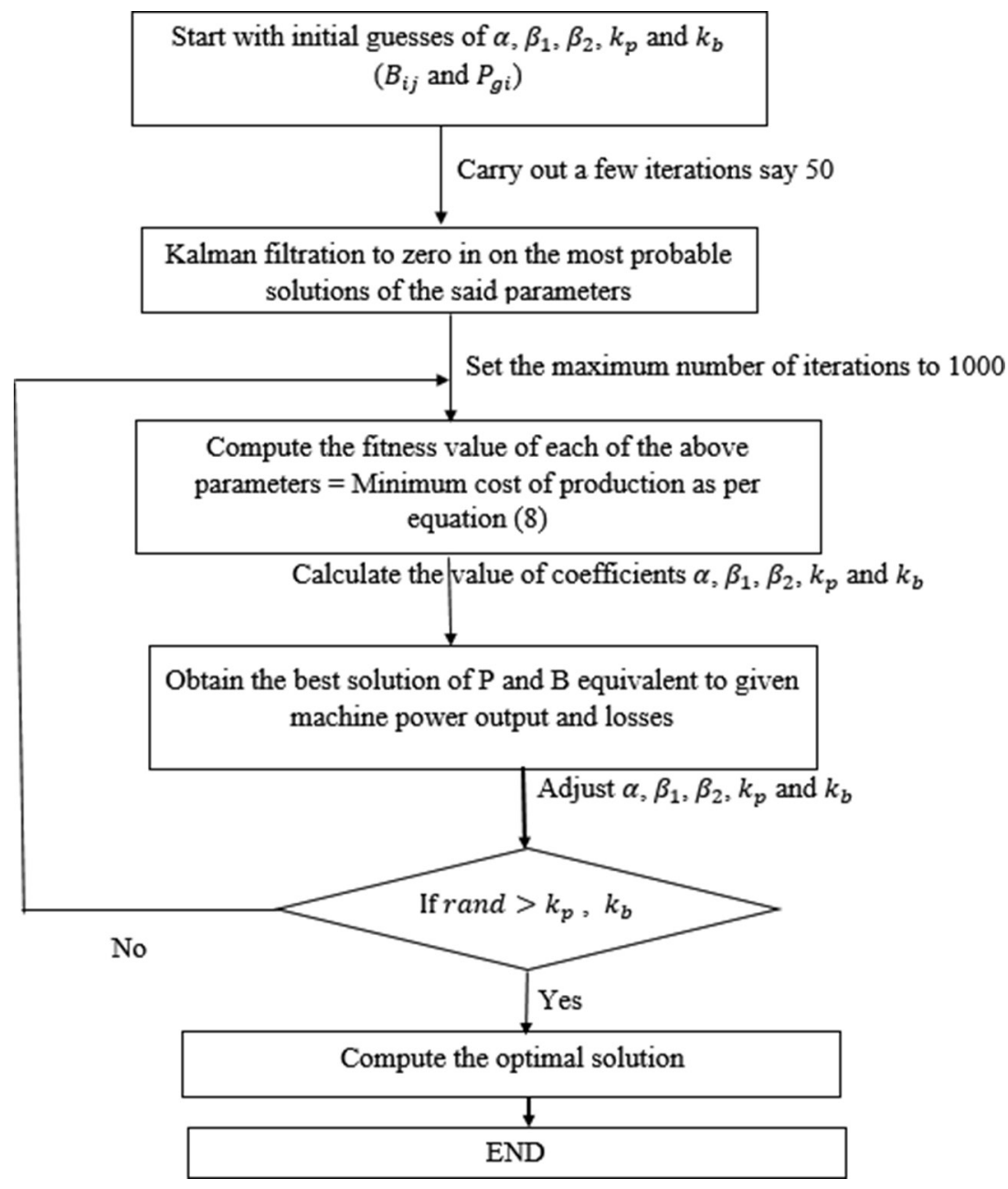

Figure 2: The FFAE optimization algorithm flow chart.

The new algorithm was developed using Matlab's optimization toolbox [49]. The algorithm's flow chart is given in Fig. 2 .

The general ant lion algorithm [47] was customized for the economic dispatch as shown in Fig.3.

\subsection{Results}

Tables 3 and 4 show the results of the economic dispatch solution using both the ant lion optimization and the proposed filter feeding optimal placement techniques for 1000 iterations in each case. 


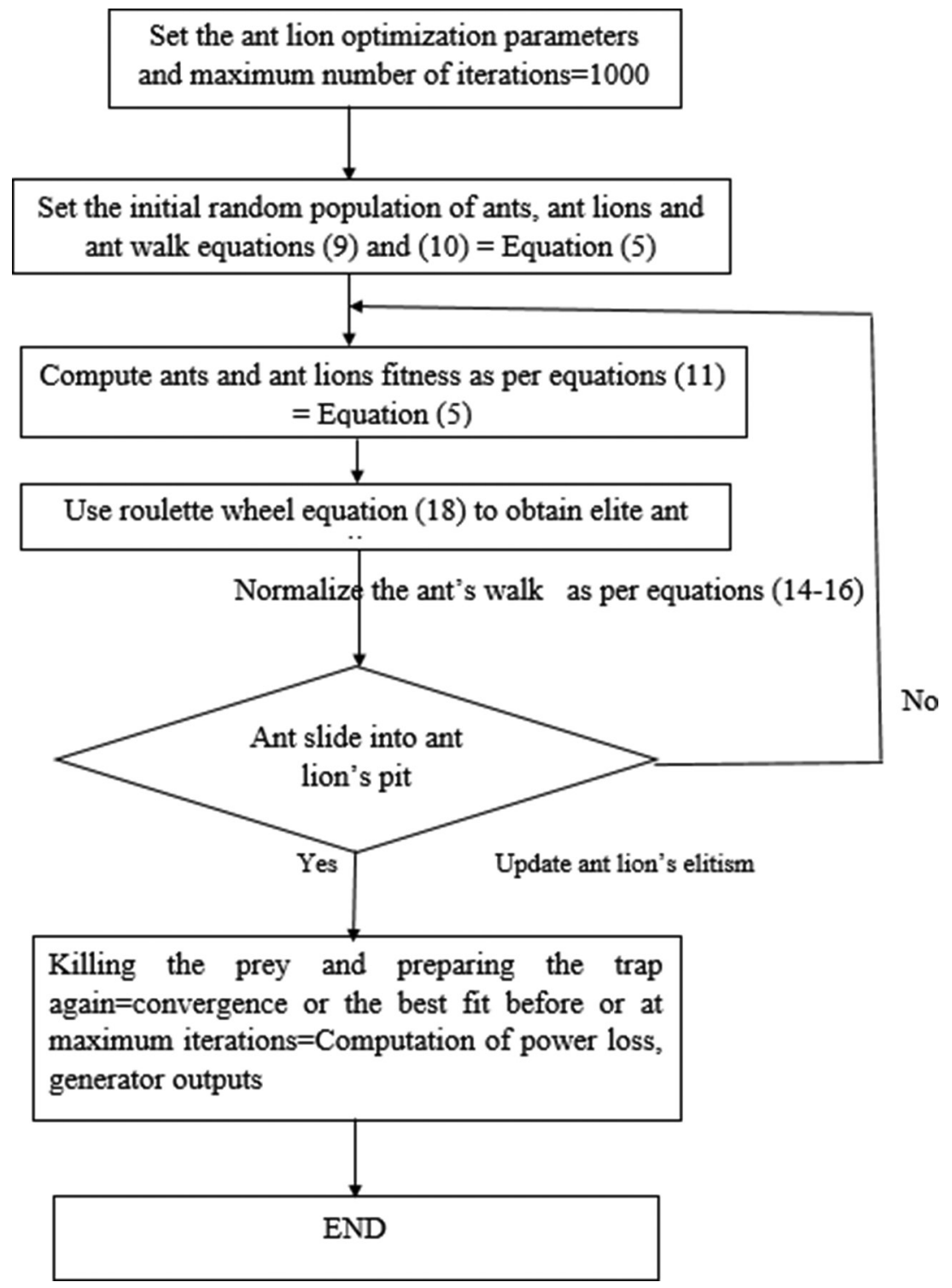

Figure 3: The ALO algorithm flow chart.

The results are further illustrated in Figs. 4 and 5.

From eqn (5), for the 39-Bus IEEE test system, the average overall system incremental fuel cost, taking into account the transmission losses, was computed as $21.54 \$ / \mathrm{MWh}$, i.e. on average, it costs 21.54 dollars to increase the system power output by $1 \mathrm{MW}$. Table 5 presents a comparison of results obtained from both algorithms. 
Tables 3: ALO economic dispatch solution results.

\begin{tabular}{|c|c|c|c|c|c|c|c|c|c|c|}
\hline $\begin{array}{l}\text { Demand } \\
\text { (MW) }\end{array}$ & 500 & 1000 & 1500 & 2000 & 2500 & 3000 & 3500 & 4000 & 4500 & 5000 \\
\hline Gen10 & & 25 & 65 & 80 & 95 & 110 & 120 & 130 & 155 & 225 \\
\hline Gen3 & 70 & 120 & 185 & 240 & 330 & 405 & 450 & 510 & 560 & 585 \\
\hline Gen4 & 85 & 130 & 190 & 235 & 325 & 365 & 425 & 495 & 550 & 565 \\
\hline Gen5 & & 50 & 80 & 115 & 125 & 165 & 210 & 252 & 315 & 455 \\
\hline Gen6 & 110 & 175 & 255 & 325 & 365 & 435 & 483 & 520 & 555 & 585 \\
\hline Gen7 & & 85 & 125 & 165 & 235 & 285 & 365 & 420 & 470 & 500 \\
\hline Gen8 & & 60 & 85 & 115 & 145 & 170 & 265 & 345 & 410 & 486 \\
\hline Gen9 & 95 & 140 & 205 & 283 & 355 & 435 & 490 & 580 & 640 & 745 \\
\hline Gen1 & 139 & 215 & 310 & 440 & 525 & 630 & 690 & 745 & 845 & 870 \\
\hline $\begin{array}{l}\text { Total } \\
\text { generation } \\
\text { (MW) }\end{array}$ & 516.89 & 1032.92 & 1548.52 & 2065.11 & 2584.95 & 3105.05 & 3626.44 & 4155.23 & 4678.15 & 5203.11 \\
\hline $\begin{array}{l}\text { Total } \\
\text { losses } \\
(\mathrm{MW})\end{array}$ & 16.22 & 32.45 & 48.75 & 65.01 & 84.63 & 105.96 & 126.78 & 155.99 & 178.98 & 203.92 \\
\hline$\%$ Losses & 3.138 & 3.14158 & 3.14817 & 3.14802 & 3.27395 & 3.41251 & 3.49599 & 3.75406 & 3.82587 & 3.91919 \\
\hline
\end{tabular}

Table 4: FFAE economic dispatch solution results.

\begin{tabular}{lllllllllll}
\hline $\begin{array}{l}\text { Demand } \\
\text { (MW) }\end{array}$ & $\mathbf{5 0 0}$ & $\mathbf{1 0 0 0}$ & $\mathbf{1 5 0 0}$ & $\mathbf{2 0 0 0}$ & $\mathbf{2 5 0 0}$ & $\mathbf{3 0 0 0}$ & $\mathbf{3 5 0 0}$ & $\mathbf{4 0 0 0}$ & $\mathbf{4 5 0 0}$ & $\mathbf{5 0 0 0}$ \\
\hline Gen10 & & 25 & 65 & 80 & 95 & 110 & 120 & 130 & 155 & 219 \\
Gen3 & 65 & 150 & 200 & 240 & 330 & 416 & 450 & 510 & 570 & 585 \\
Gen4 & 85 & 130 & 190 & 235 & 325 & 365 & 425 & 495 & 550 & 565 \\
Gen5 & & 50 & 80 & 115 & 125 & 165 & 210 & 255 & 355 & 455 \\
Gen6 & 110 & 195 & 305 & 325 & 365 & 435 & 485 & 520 & 555 & 585 \\
Gen7 & & 85 & 125 & 165 & 235 & 285 & 365 & 420 & 470 & 500 \\
Gen8 & & 60 & 85 & 115 & 145 & 170 & 265 & 345 & 425 & 486 \\
Gen9 & 95 & 140 & 205 & 285 & 355 & 435 & 490 & 605 & 640 & 745 \\
Gen1 & 140 & 215 & 350 & 440 & 525 & 630 & 696 & 745 & 845 & 870 \\
Total & 515.35 & 1032.41 & 1548.26 & 2065.82 & 2584.34 & 3105.76 & 3626.92 & 4156.22 & 4678.65 & 5203.11 \\
generation & & & & & & & & & & \\
(MW) & & & & & & & & & & \\
Total & 15.64 & 32.32 & 48.62 & 65.12 & 84.55 & 105.62 & 126.57 & 156.11 & 178.98 & 203.21 \\
losses & & & & & & & & & & \\
(MW) & & & & & & & & & & \\
\% Losses & 3.0348 & 3.1305 & 3.1403 & 3.1522 & 3.2716 & 3.4007 & 3.4897 & 3.7560 & 3.8254 & 3.9055 \\
\hline
\end{tabular}


Generator power versus total connected load curve from the

Filter feeding allogenic engineering opmitization
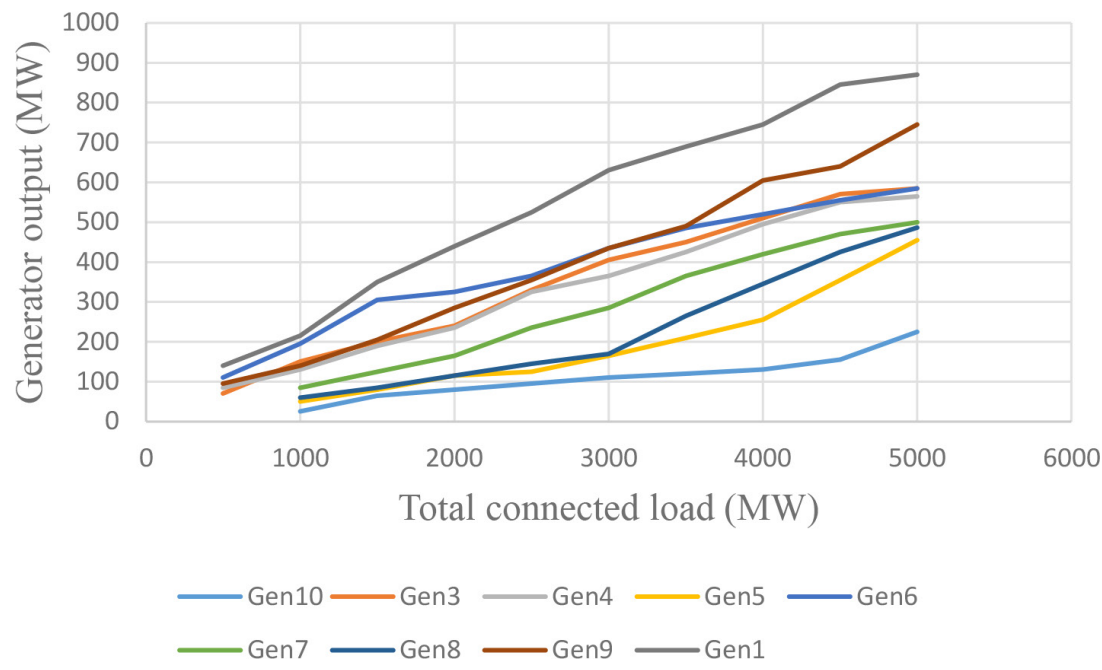

Figure 4: Generator output-load curves from the FFAE optimizer.

Generator power versus total connected load curve from the Ant lion optimizaton solution
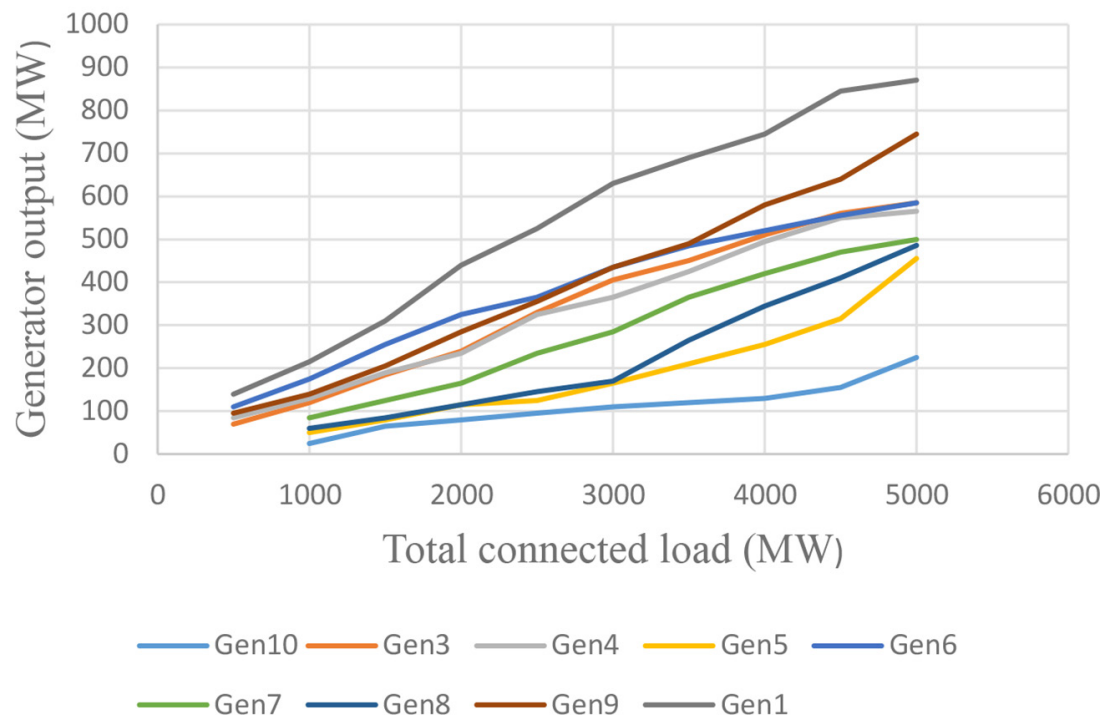

Figure 5: Generator output-load curves from the ALO optimizer. 
Tables 5: Comparison of FFAE and ALO economic dispatch solution results.

\begin{tabular}{lllllll}
\hline & \multicolumn{3}{c}{ FFAE } & & & ACO \\
Demand & $\begin{array}{l}\text { Total } \\
\text { generation } \\
\text { (MW) }\end{array}$ & $\begin{array}{l}\text { losses } \\
(\mathbf{M W})\end{array}$ & \% Losses & $\begin{array}{l}\text { Total } \\
\text { generation } \\
(\mathbf{M W})\end{array}$ & $\begin{array}{l}\text { Total losses } \\
(\mathbf{M W})\end{array}$ & $\begin{array}{l}\text { \% } \\
\text { Losses }\end{array}$ \\
\hline $\mathbf{5 0 0}$ & 515.35 & 15.64 & 3.03483 & 516.89 & 16.22 & 3.13800 \\
$\mathbf{1 0 0 0}$ & 1032.41 & 32.32 & 3.13054 & 1032.92 & 32.45 & 3.14158 \\
$\mathbf{1 5 0 0}$ & 1548.26 & 48.62 & 3.1403 & 1548.52 & 48.75 & 3.14817 \\
$\mathbf{2 0 0 0}$ & 2065.82 & 65.12 & 3.15226 & 2065.11 & 65.01 & 3.14802 \\
$\mathbf{2 5 0 0}$ & 2584.34 & 84.55 & 3.27163 & 2584.95 & 84.63 & 3.27395 \\
$\mathbf{3 0 0 0}$ & 3105.76 & 105.62 & 3.40078 & 3105.05 & 105.96 & 3.41251 \\
$\mathbf{3 5 0 0}$ & 3626.92 & 126.57 & 3.48974 & 3626.44 & 126.78 & 3.49599 \\
$\mathbf{4 0 0 0}$ & 4156.22 & 156.11 & 3.75606 & 4155.23 & 155.99 & 3.75406 \\
$\mathbf{4 5 0 0}$ & 4678.65 & 178.98 & 3.82546 & 4678.15 & 178.98 & 3.82587 \\
$\mathbf{5 0 0 0}$ & 5203.11 & 203.21 & 3.90555 & 5203.11 & 203.92 & 3.91919 \\
\hline
\end{tabular}

\subsection{Discussion}

The new optimization method gave better results as compared to the tried and tested ant lion optimization technique as shown by the results in Tables 3 and 4 . The total losses ranged from $3.138 \%$ to $3.919 \%$ and from $3.035 \%$ to $3.906 \%$ of the total generated power for the ALO and FFAE optimization techniques, respectively. The new optimization method was able to successfully solve the economic dispatch problem under variable load demand as it happens in practical power systems and with a reasonable computation error. The authors believe that the algorithm is poised to perform even much better with time due to the continuous improvement in the formulation of the oceanic predator-prey equations.

The input-output curve of a generator is modelled by the quadratic function given by eqn (2), assuming that the incremental cost curves of each unit are monotonically increasing linear functions. The above curves in Figs. 4 and 5 are approximately quadratic for all practical purposes, thus a good solution for the economic dispatch problem is represented by eqn (2).

Making the problem more multi-objective by adding more constraints such as system reliability assessment, emissions and spinning reserve will make the curve more quadratic, but the trade-off during the solution of the same gets more delicate and complicated.

The FFAE method took more computation time owing to the long process of solving for the predator-prey eqns (10) and (11) both of which have five unknown parameters.

The authors believe that Kalman filtration will form a good approach in handling interactive multi-objective economic dispatch problems going forward due to the very sensitive level of balancing required for the various competing aspects.

Emerging factors such as the emergence of virtual power plants, block chain's peer-to-peer electricity trade, prosumers, the internet of things and battery storage will all have to be considered part of the system and operational constraints. 


\section{CONCLUSION}

Accurate solution of the economic dispatch problem remains a critical cog in the technical and financial sustainability of the power utility business. This goes hand in hand with other major concerns such as the harmful emissions. As more power utilities and countries adopt the horizontal business models, minimization of operational costs will become even more important. Competition in the generation segment will mean companies have to operate at the lowest possible costs as profit margins will inevitably continue to tumble.

It is for this reason that research of more heuristic and hybrid optimization methods for economic dispatch solution will continue to attract a lot of research attention.

The growth of competition occasioned by complete liberalization of the energy sector, deeper penetration of renewable energy sources and the expansion of emerging technologies such as the hydrogen resource will make research into this area even more attractive. The ever-evolving energy matrix will continue to make research in this area even more attractive. A good example is the growth of battery storage vis-à-vis the increasing definition of the same as generation will form part of evolving operational constraints that need to be taken into account going forward.

For future research work, there is a need to incorporate a generation planning component vis-à-vis the load centres in the generator cost function $F$ in eqn (1). This is because poor generation planning directly imparts on the cost of delivery of the power in terms of losses and more cost incurred in system stability even if there is enough generation capacity.

The new method can be improved through further refining of the predator-prey equations as marine biologists continue to study and understand the ecosystem engineers better.

\section{REFERENCES}

[1] Nwulu, N.I. \& Agboola, P.O., Modelling and predicting electricity consumption using artificial neural networks. Proceedings of the 11th International Conference on Environmental \& Electrical Engineering, Venice, Italy, 2012.

[2] Damisa, U., Nwulu, N.I. \& Sun, Y., Microgrid energy and reserve management incorporating prosumer behind the-meter resources. IET Renewable Power Generation, 12(8), pp. 910-919, 2018. https://doi.org/10.1049/iet-rpg.2017.0659

[3] Fahrioglu, M. \& Nwulu, N.I., Investigating a ranking of loads in avoiding potential power system outages. Journal of Electrical Review (Przeglad Elektrotechniczny), Warsaw, Poland, 88(11a), pp. 239-242, 2012.

[4] Nwulu, N.I. \& Fahrioglu, M., A neural network model for optimal demand management contract design. Proceedings of the 10th International Conference on Environmental \& Electrical Engineering, Rome, Italy, 2011.

[5] Musasa, K., Nwulu, N.I., Gitau, M.N. \& Bansal, R., Review on DC collection grids for offshore wind farms with HVDC transmission system. IET Power Electronics, 10, pp. 2104-2115, 2017. https://doi.org/10.1049/iet-pel.2017.0182

[6] Gbadamosi, S., Nwulu, N.I. \& Sun, Y., Multi-objective optimization for composite generation and transmission expansion planning considering offshore wind power and feed in tariffs. IET Renewable Power Generation, 12(14), pp. 1687-1697, 2018. https://doi. org/10.1049/iet-rpg.2018.5531

[7] Narvaez, D.M.D., Application of the gradient method in the economic dispatch. Contemporary Engineering Sciences, 11(96), pp. 4761-4768, 2018. https://doi.org/ $10.12988 /$ ces. 2018.89513 
[8] Arumugam, P. \& Subramanian, C., Power search algorithm for combined economicemission dispatch problems considering valve point effects in economic load dispatch. Turkish Journal of Electrical Engineering and Computer Sciences, 25, pp. 4647-4656, 2017. https://doi.org/10.3906/elk-1705-42

[9] Rao, H.A. \& Reddy, V.B., Economic dispatch using a simple probabilistic method, a case study of Karnataka power grid. International Journal of Recent Research Aspects, Special Issue, pp. 16-19, 2018.

[10] Navariya, S. \& Singhal, P.K., Review on solution techniques for solving power system dynamic economic dispatch problem. International Journal of Engineering Trends and Technology, 51(1), pp.16-19, 2017. https://doi.org/10.14445/22315381/ijett-v51p203

[11] Nwohu, M.N. \& Paul, O.O., Evaluation of economic load dispatch problem in power generating stations by the use of ant colony search algorithm. International Journal of Research Studies in Electrical and Electronics Engineering, 3(1), pp. 20-29, 2017. https://doi.org/10.20431/2454-9436.0301004

[12] Akkaş, Ö.P., Çam, E., Eke, İ. \& Arıkan, Y., New optimization algorithm for application to environmental economic load dispatch in power systems. Electrica, 18(2), pp. 133-142, 2018. https://doi.org/10.5152/iujeee.2018.1825

[13] Kumar, D.G. \& Reddy, P.U., Combined emission dispatch and economic dispatch of power system including renewable sources. International Journal of Advanced Research in Electrical, Electronics and Instrumentation Engineering, 6(5), pp. 3696-3711, 2017.

[14] Alarcon, J.A., Rivera, S.R. \& Santamaria, F., Strategies for economic dispatch with intermittent renewable power plants. Vision Electronica, 12(2), pp. 173-179, 2018. https://doi.org/10.14483/22484728.14072

[15] Akkaş, Ö.P., Arikan, Y. \& Çam, E., Load dispatch for a power system in terms of economy and environment by using VIKOR method. Journal of Science and Engineering, 19(57), pp. 733-741, 2017. https://doi.org/10.21205/deufmd.2017195766

[16] Abdelaziz, A.Y., Ali, E.S. \& Abd Elazim, S.M., Combined economic and emission dispatch solution using flower pollination algorithm. Electrical Power and Energy Systems, 80, pp. 264-274, 2016. https://doi.org/10.1016/j.ijepes.2015.11.093

[17] Ghorbani, N. \& Babaei, E., Exchange market algorithm for economic load dispatch. International Journal of Electrical Power and Energy Systems, 75, pp. 19-27, 2016. https://doi.org/10.1016/j.ijepes.2015.08.013

[18] Rao, S.N.M. \& Kumar, N., Optimal load dispatch solution of power system using enhanced harmony search algorithm. European Journal of Electrical Engineering, 20, pp. 469-483, 2018. https://doi.org/10.3166/ejee.20.469-483

[19] Xiong, G. et al., A novel method for economic dispatch with across neighborhood search: A case study in a provincial power grid, China. Complexity, 2018, article ID 2591341, pp. 1-19, 2018.

[20] Touma, J.H., Study of the economic dispatch problem on IEEE 30-Bus system using whale optimization. International Journal of Engineering Technology and Sciences, 5(1), pp. 11-18, 2016.

[21] Basu, M., Kinetic gas molecule optimization for non-convex dispatch problem. International Journal of Electric Power \& Energy Systems, 80, pp. 323-332, 2016. https://doi. org/10.1016/j.ijepes.2016.02.005

[22] Mansor, M.H., Musirin, I. \& Othman, M.M., Immune log-normal evolutionary programming for solving economic dispatch problem with prohibited operating zones. 20174 th International Conference on Industrial Engineering and Applications (ICIEA), Nagoya, Japan, pp. 163-167, 2017. 
[23] Elsayed, W.T., Hegazy, Y.G., Bendary, F.M. \& El-bages, M.S., Modified social spider algorithm for solving the economic dispatch problem. Engineering Science and Technology Journal, 19, pp. 1672-1681, 2016. https://doi.org/10.1016/j.jestch.2016.09.002

[24] Taheri, B., Aghajani, G. \& Sedaghat, M., Economic dispatch in a power system considering environmental pollution using a multi-objective particle warm optimization algorithm based on the Pareto criterion and fuzzy logic. International Journal of Energy \& Environmental Engineering, 8, pp. 99-107, 2017. https://doi.org/10.1007/s40095017-0233-9

[25] Gherbi, Y.A. \& Gherbi, F.Z., The combined economic environmental dispatch using new hybrid metaheuristic method. Energy, 115, pp. 468-477, 2016. https://doi.org/ 10.1016/j.energy.2016.08.079

[26] Musau, M.P., Odero, N.A. \& Weseka, C.W., Multi area multi objective dynamic economic dispatch with renewable energy and emissions. 2016 IEEE International Energy Conference, Leuven, Belgium, pp. 1-6, 2016.

[27] Sen, T. \& Mathur, H.D., A new approach to solve economic dispatch problem using a hybrid ACO-ABC-HS optimization algorithm. International Journal of Electrical Power and Energy Systems, 78, pp. 735-744, 2016. https://doi.org/10.1016/j.ijepes.2015.11.121

[28] Pradhan, M., Roy, P.K. \& Pal, T., Grey wolf optimization applied to economic load dispatch problems. International Journal of Electrical Power \& Energy Systems, 83, pp. 325-334, 2016. https://doi.org/10.1016/j.ijepes.2016.04.034

[29] Neto, J.X.V. et al., Solving non-smooth economic dispatch by a new combination of continuous grasp algorithm and differential evolution. International Journal of Electric Power \& Energy Systems, 84, pp. 13-24, 2017. https://doi.org/10.1016/j.ijepes.2016.04.012

[30] Hua, W. et al., Stochastic environmental and economic dispatch of power systems with virtual power plant in energy and reserve markets. International Journal of Smart Grid and Clean Energy, 7(4), pp. 231-239, 2018. https://doi.org/10.12720/sgce.7.4.231-239

[31] Kheshti, M. et al., An effective lightning flash algorithm solution to large scale nonconvex economic dispatch with valve-point and multiple fuel options on generation units. Energy, 129, pp.1-15, 2017. https://doi.org/10.1016/j.energy.2017.04.081

[32] Rao, H.X. \& Huang, J., A novel algorithm for economic load dispatch of power systems. Neuro Computing, 171, pp. 1454-1461, 2016. https://doi.org/10.1016/j.neucom.2015.07.107

[33] Dosoglu, K.M. et al., Symbiotic organisms search optimization algorithm for economic/emission dispatch problem in power systems. Neural Computing and Applications, 29(3), pp. 721-727, 2018. https://doi.org/10.1007/s00521-016-2481-7

[34] Niazazari, I., Gashteroodkhani, O.A. \& Azari, A.N., A novel economic dispatch in power grids based on enhanced firework algorithm. European Journal of Electrical and Computer Engineering, 3(4), pp. 1-5, 2019. https://doi.org/10.24018/ejece.2019.3.4.96

[35] Haroon, N.S. et al., Multiple fuel machine power economic dispatch using stud differential evolution. Energies, 11(6), pp. 1-20, 2018. https://doi.org/10.3390/en11061393

[36] Zakian, P. \& Kaveh, A., Economic dispatch of power system using an adaptive charged system search algorithm. Applied Soft Computing Journal, 73, pp. 607-622, 2018. https://doi.org/10.1016/j.asoc.2018.09.008

[37] Cui, S., Wang, Y.-W., Liu, X. \& Lin, X.-K., Distributed auction optimization algorithm for the non-convex economic dispatch problem based on the gossip communi- 
cation mechanism. International Journal of Electrical Power \& Energy Systems, 95, pp. 417-426, 2018. https://doi.org/10.1016/j.ijepes.2017.09.012

[38] Dihem, A., Salhi, A., Naimi, D. \& Bensalem, A., Solving smooth and non-smooth economic dispatch using water cycle algorithm. 5th International Conference on Electrical Engineering, Boumerdes, Algeria, pp. 1-6, 2017.

[39] Ali, E.S. \& Abd Elazim, S.M., Mine blast algorithm for environmental economic load dispatch with valve loading effect. Neural Computing and Applications, 30, pp. 261-270, 2016. https://doi.org/10.1007/s00521-016-2650-8

[40] Mansor, M.H. et al., A hybrid optimization technique for solving economic dispatch problem, IOP conference series. Journal of Physics: Conference Series, 1049, pp. 1-8, 2018. https://doi.org/10.1088/1742-6596/1049/1/012035

[41] Hu, X., Wang, D., Qu, H. \& Shi, X., Prediction research of red tide based on improved FCM. Mathematical Problems in Engineering, 2016, article ID 9618706, pp. 1-8, 2016.

[42] Lovvon, J.R., Baduini, C.L. \& Hunt Jr., G.L., Modelling underwater visual and filter feeding by planktivorous shearwaters unusual sea conditions. Ecology Society of America, 82(8), pp. 2342-2356, 2001. https://doi.org/10.1890/0012-9658(2001) 082[2342:muvaff] 2.0.co;2

[43] Jeong, H.J., Yoo, Y.D., Park, J.Y., Song, J.Y., Kim, S.T., Lee, S.H., Kim, K.Y. \& Yih, W.H., Feeding by phototrophic red-tide dinoflagellates: five species newly revealed and six species previously known to be mixotrophic. Aquatic Microbial Ecology, 40, pp. 133-150, 2005. https://doi.org/10.3354/ame040133

[44] Walles, B., The Role of Ecosystem Engineers in the Ecomorphological Development of Intertidal Habitats, PhD Thesis, Wageningen University, pp. 329-338, 2018.

[45] Grewal, M.S. \& Andrews, A.P., Kalman Filtering: Theory and Practice using MATLAB, John Wiley and Sons Inc., Chapters 4 and 5, pp. 114-200, 2001.

[46] Mirjalili, S., Multi-objective ant lion optimizer (MOALO), 2019, https://www.mathworks.com/matlabcentral/fileexchange/58460-multi-objective-ant-lion-optimizermoalo.

[47] Daniel, L. \& Chaturvedi, K.T., Economic load dispatch using ant lion optimization. International Journal of Engineering Trends and Technology, 67(4), pp. 81-84, 2019. https://doi.org/10.14445/22315381/ijett-v67i4p218

[48] Faisal, Z. \& Hatata, A.Y., Ant lion optimizer for optimum economic dispatch considering demand response as a visual power plant. Electric Power Components and Systems, 47(6-7), pp. 1-15, 2019. https://doi.org/10.1080/15325008.2019.1602799

[49] Coleman, T.F., Branch, M.A. \& Grace, A., Optimization Toolbox-for Use with MATLAB_, User's Guide, Version 2, Math Works, Inc., Natick, MA, 1999. 